\title{
Single-site strategic capacity planning considering renewal, maintenance, inventory, taxes and cash flow management
}

\author{
Ernest Benedito ${ }^{1}$, Albert Corominas ${ }^{1}$, Carme Martínez ${ }^{1}$, Marta Mas-Machuca ${ }^{2}$ \\ ${ }^{1}$ Universitat Politècnica de Catalunya (UPC), Barcelona, Spain; and ${ }^{2}$ Universitat \\ Internacional de Catalunya, Barcelona, Spain
}

\begin{abstract}
This paper deals with strategic capacity planning of a single-site manufacturing system. We propose a MILP model that includes relevant business aspects and possibilities, some of which are only partially or not at all found in the literature. Specifically, we consider decisions on expansion, reduction and renewal of production capacity, and acquisition of storage capacity. In addition, we model aspects such as a) maintenance costs and unit variable costs depending, respectively, on age and characteristics of facilities, b) seasonality of the demand, and c) cash flow management, including taxes and, therefore, depreciation of assets. The model maximises the after-tax cash balance at the end of the planning horizon. We also present a computational experiment with 54 instances to show that the model can be solved for a wide range of sizes in a reasonable computing time using comercial software.
\end{abstract}

Key words: strategic capacity planning; manufacturing; mathematical programming models

\section{Introduction}

In this paper, we propose a new deterministic model for strategic capacity planning of a single-site manufacturing system. Unlike previously published models, this one incorporates the most relevant decisions on strategic capacity planning.

Our purpose is twofold: to demonstrate that these decisions can be incorporated in a MILP model and to establish the ranges of dimensions in which the model can be solved within an affordable computing time using commercial software. In this way, it is shown that the model could be used as a decision support tool. 
Production system capacity is sometimes defined as the volume of products that can be generated by a system in a given period. However, this definition is valid only when the system generates a single product or a set of very homogeneous products. Otherwise, the volume of products obtained depends on the product mix. Hence, what generally defines capacity is not the volume of outputs that can be generated by a system in a given time, but the availability of various types of productive resources.

Capacity management is very important for an organisation because it affects results significantly. Traditionally, the literature on operations management has distinguished between tactical and strategic capacity planning. The former, also called aggregate planning, refers to medium term, typically one year, and deals with production and inventory management considering the possibility of modifying the size of the staff and the amount of working time for example, by using overtime, but not equipment. On the other hand, strategic capacity planning refers to the variation of facilities in the long and medium term, typically several years. However, in our opinion, the essential difference between tactical and strategic capacity planning does not lie in the length of the time horizon, but in the consideration of assets as given or as the object of decisions, respectively. Classifying a time interval as medium or long term depends not only on its duration, but also on the pace of changes in technology and demand, e.g., in the TFTLCD and semiconductor manufacturing industries, strategic decisions concerning the number of machines and their technology may have to be taken within a horizon of only a few months (Geng et al., 2009; Chen et al., 2013).

Decisions involved in strategic capacity planning usually have a strong impact on an organisation and its results since they tend to be associated with considerable investments. Moreover, once implemented, decisions are difficult to reverse, and if you do reverse them, it is at a high cost. Therefore, there is a need for efficient tools to deal with them.

Many mathematical programming models have been proposed with this purpose, as briefly shown in Section 2. Analysis of these models reveals that, although they all take into account some of the relevant factors, none incorporates all the desirable characteristics.

The types of decisions and aspects to consider in strategic planning capacity are diverse and their importance depends on the specific case under consideration. Martínez-Costa 
et al. (2014) identified up to nine kinds of decisions and nine external factors considering strategic capacity planning of sigle-site and multi-site manufacturing systems. However, we believe that those discussed below are among the most significant.

All models consider the possibility of acquiring additional equipment throughout the planning horizon to replace obsolete equipment, introduce new technologies or satisfy a growing demand (Çathay et al., 2003). However, some authors (e.g., Olhager et al., 2001; Geng and Jiang, 2009) point out that decisions to be made concern expansion and reduction of equipment as a result of a fall in demand caused by an economic recession or a product being at the end of its life cycle. A modification in the characteristics of equipment involves changes in unit fixed and variable costs. However, the latter are usually negligible because these costs are regarded as data. The age of equipment also generally has a major impact on its maintenance costs.

Seasonality of demand is overlooked in many strategic capacity planning models because the time horizon is divided into years and for each period a global forecast of demand is used, regardless of its distribution throughout the year. In high seasonality scenarios, this approach cannot provide optimum production and storage capacities and may even result in configurations unable to meet the expected demand. Thus, as noted in Bradley and Glynn (2002), decisions about capacity must involve production and inventory management.

Indeed, financial constraints affect strategic planning capacity policies substantially. It is generally assumed that the organisation finances its plans with its own funds and that the use of net present value as a decision criterion is acceptable. Clearly, this is not the case in many real situations, especially those concerning projects involving significant investments. Moreover, taxes on profits can be an important component of cash flows, with the consequent impact on finances. And when they are considered, depreciation of assets must be calculated.

All these elements, i.e., expansion and reduction, maintenance costs and unit variable costs depending, respectively, on the age and characteristics of facilities, seasonality of demand, cash flow management, including taxes and, therefore, depreciation of assets, may be incorporated in a single mathematical program which, unless very large, can currently be solved within a reasonable computing time. 
The layout of the rest of the paper is as follows. The next section provides a brief review of the literature on mathematical models for strategic capacity planning of single-site manufacturing systems. Section 3 sets the adopted assumptions and proposes the corresponding mixed-integer linear program. Section 4 describes a computational experiment, including the generation of data sets. The paper ends with Section 5, which contains the conclusions and future lines of research.

\section{Literature review}

This section is a review of literature on mathematical programming dealing with strategic capacity planning problems of single-site manufacturing companies. Capacity Planning in Operations Management has been an important research topic for many years. Luss (1982) was the first literature review on capacity expansion. Van Mieghem (2003), Wu et al. (2005), Julka et al. (2007) and Geng and Jiang (2009) also provided literature reviews on this topic. The most recent review is Martínez-Costa et al. (2014), which describes the major decisions and conditioning factors involved in strategic capacity planning, and outlines the mathematical programming models proposed in the literature to deal with the above problems.

With regard to capacity-size decisions, most deterministic single-site models consider capacity expansion as the only option to adapt capacity to demand, assuming non decreasing market demand over time (the most recent are Rajagopalan \& Swaminathan, 2001; Wang \& Lin, 2002; Çatay et al., 2003; Wang \& Hou, 2003; Zhang et al., 2012; Lim et al., 2013). Atamtürk \& Hochbaum (2001) highlights the opportunity of outsourcing as another way to meet a growing demand.

However, in certain economic environments, companies are forced to reduce production and consider disinvestment in capacity. Rajagopalan \& Soteriou (1994), Rajagopalan (1998), Wang et al. (2007a) and Yang et al. (2009) present deterministic models that include the possibility of capacity expansion and reduction.

A few studies address the problem of capacity expansion and replacement of equipment due to physical deterioration over time and availability of new technology (e.g., Rajagopalan, 1992; Chand et al., 2000; Wang et al., 2007b; Mitra et al., 2014). Although the depreciation of assets is considered in relation with the expansion and replacement decisions, maintenance costs depending on the age of the assets have not been considered in the previous literature. 
When capacity planning involves multiple resources and several products sharing some capacity resources, capacity and allocation decisions must be made simultaneously. Some examples of models that jointly address these decisions are proposed by Wang et al. (2007a), Yang et al. (2009), Zhang et al. (2012) and Lim et al. (2013), among others. The joint consideration of capacity investment decisions and production and inventory decisions is addressed only in a few publications (e.g., Thomas \& Bollapragada, 2010; Zhang et al., 2012; Lim et al., 2013; Mitra et al., 2014). However, in some industries the interaction between capacity and inventory decisions is significant. In this situation, storage and production capacity should be considered jointly (as in the model by Mitra et al., 2014).

Closely related to investment in capacity are financial decisions. Companies may require huge investments in capacity expansion, and so they must make decisions on how to finance these investments, e. g., increment of equity by means of loans and bonds, etc.. Traditional capacity planning models implicitly assume that all investment is financed by equity. Other models (found in Wang et al., 2007b; Yang et al., 2009, among others) investigated the capacity expansion problem under budget constraints. Despite their relevance, there is a lack of research on single-site deterministic models that integrate financial and capacity decisions in their formulation.

Investment and financial decisions have an impact on cash flow, operating income, costs and taxes (Martínez-Costa et al., 2014). Corporate taxes should be included in the cash flow formulation while studying a capacity planning problem because they represent a real significant expenditure for the company. Paying taxes reduces the budget for new assets. Despite this, only a few capacity planning models include tax in profits (e.g., Thomas \& Bollapragada, 2010).

As can be seen, several studies consider some of the above aspects. However, none of them integrates all the decisions and conditioning factors (Martínez-Costa et al., 2014).

This paper proposes a discrete-time finite horizon mathematical programming model for optimising capacity decisions under deterministic demand for multiple resource types and multi-product manufacturing systems. At the best of our knowledge, our model is the first to simultaneously address capacity, production and inventory decisions to meet demand over a multiperiod horizon and cash flow management. Since the objective function maximises the cash flow at the end of the planning horizon, the model 
incorporates several economic and financial variables, depreciation of assets and corporate tax considerations.

\section{Problem statement and model formulation}

\subsection{Problem statement}

We consider a system that must satisfy the demand for various types of products throughout a finite time horizon. To do this, the system has a single-site facility and may acquire various types of production equipment to manufacture the products. This equipment determines the production capacity of the system. The system also has a storage capacity, which can be extended throughout the planning horizon. To carry out operations, the system has a limited borrowing capacity and a bank account where payments and receipts are recorded.

The problem consists in making production and storage capacity decisions that optimise system performance within a discrete time and finite horizon considering the most relevant flows: logistic flow (defined by production, storage and sale of products), cash flow (collections and payments), and acquisition, replacement and reduction of production equipment. Note that, although the aim is to optimise strategic rather than tactical decisions, some of the latter are to be considered because of their relationship to production and storage capacity decisions. The problem is defined under the following assumptions:

\section{Initial conditions assumption:}

The system may have had business activity before the beginning of the planning horizon. That is, the system may have acquired productive equipment and storage capacity before the starting period, and may have collections and payments pending at the beginning of the starting period.

\section{Demand assumption:}

The demand in each period is known, is totally satisfied by the production system and cannot be deferred.

Manufacturing and storage capacity assumptions:

The manufacturing system consists of several types of production equipment. In this context, production equipment refers to any machinery, production line, installation or facility such that acquisition of any of those leads to an increase in production capacity. 
Production capacity can increase or decrease in each period by buying or selling production equipment.

Storage capacity is limited and can be expanded by adding new facilities to existing ones. Increasing storage capacity requires a payment. There are a finite number of possible storage capacities and they are numbered in the increasing order of their values.

Acquisitions of production equipment and storage facilities are paid when they are available for use. Part of the cost of acquisition is assigned to lengthening the useful life of each asset using a straight-line depreciation method.

Production and storage maintenance costs are paid each period. The former depend on the type, quantity and age of production equipment whereas the latter depend on the existing storage capacity and age of equipment. These payments increase with capacity and age of equipment. Thanks to the maintenance tasks, the assets preserve the original properties.

In view of the above, we can assume that variable production and storage costs depend on current capacities regardless of age of equipment.

\section{Financial and tax assumptions:}

The company has a bank account to make and receive payments. At the end of each period, the account generates an interest income or an interest charge depending on whether the account balance is positive or negative.

Borrowing capacity is limited. Flows into and out of bank account are the following: collections such as bank interest, product and production equipment sales; and payments such as bank interest, operating costs, purchase of production equipment and storage capacity, maintenance and variable costs, and taxes.

Taxable income is calculated annually from the profit and loss account. The profit and loss account includes the most significant revenues and expenses, such as revenues, bank interest incomes and charges, fixed costs, fixed and variable operating costs, nonamortisable costs of new production equipment and storage capacity acquisition, depreciation of assets, profit or loss from production equipment sales, and product inventory value. Negative taxable income for a year can be carried forward to reduce future taxable income as long as the company has future positive taxable profits to offset losses. VAT repercussions are not considered in the cash flow model. 
We make no specific assumptions about how fixed cost increases with capacity (note that more restrictive assumptions could simplify the model).

\section{Optimisation criteria and decision variables assumptions:}

The ultimate objective is to maximise the cash balance at the end of the planning horizon after making and receiving all payments and selling all assets for their residual value. The problem consists in determining, for each period, the quantity to be produced (tactical decisions) and production and storage capacities (strategic decisions) that maximise the cash balance. Production amounts (tactical decisions) can have real values. Although they could be integer, the real value assumption might improve the performance of the resolution without introducing significant errors in the solutions. The number of units of production equipment (strategic decision) must be integer.

\subsection{Model formulation}

\section{Data:}

Let $N$ be the number of types of product to be manufactured by the company within a planning horizon divided into $T$ periods. As a result of the tax liabilities of the company, the planning horizon is also divided into $Y$ years, each one of them comprising an integer number of periods; let $\Gamma_{k}$ be the first period of year $k$. Let $v_{M}$ be the number of types of production equipment that can be acquired by the company to manufacture the products. Every i $\epsilon\left\{1, \ldots, v_{M}\right\}$ may represent one or a set of machines, production lines, installations or facilities and limits the production capacity of the system. Table 1 lists the dimensional parameters of the model. The rest of parameters are shown in Tables 24, grouped by investment and cost data, financial and tax parameters, and miscelaneous parameters.

Table 1 Dimensional parameters

\begin{tabular}{l|l}
\hline Symbol & Definition \\
\hline$T$ & Number of periods of the planning horizon. \\
$Y$ & Number of years of the planning horizon. \\
$\Gamma_{k}$ & First period of year $k(k=1, \ldots, Y)$. \\
$N$ & Number of types of products. \\
$v_{M}$ & Number of types of production equipment. \\
$v_{W}$ & Number of levels of storage capacities. \\
$B$ & The period in which the oldest equipment still available at the beginning of \\
& the planning horizon was acquired. The first period of the planning horizon \\
\hline
\end{tabular}


is period 1. If no production equipment was acquired before the beginning of the planning horizon, $B=1$.

Table 2 Investment and cost data

\begin{tabular}{|c|c|}
\hline Symbol & Definition \\
\hline$C M_{i t}$ & $\begin{array}{l}\text { Non-amortisable cost required to set up one unit of production equipment of } \\
\text { type } i \text { in period } t\left(i=1, \ldots, v_{M} ; t=1, \ldots, T\right) \text {. }\end{array}$ \\
\hline$C W_{j i t}$ & $\begin{array}{l}\text { Non-amortisable cost required to increase storage capacity from } W_{j} \text { to } W_{i} \text { in } \\
\text { period } t\left(i=1, \ldots, v_{W} ; j=0, \ldots, i-1 ; t=1, \ldots, T\right) \text {. }\end{array}$ \\
\hline$M M_{i \tau t}$ & $\begin{array}{l}\text { Maintenance cost for period } t \text {, corresponding to one unit of production } \\
\text { equipment of type } i \text {, acquired in period } \tau\left(i=1, \ldots, v_{M} ; t=1, \ldots, T, \tau=\right. \\
B, \ldots, t) \text {. }\end{array}$ \\
\hline$M W O_{t}$ & $\begin{array}{l}\text { Maintenance cost for period } t \text {, corresponding to initial storage capacity } W_{0}(t \\
=1, \ldots, T)\end{array}$ \\
\hline$M W_{i \tau t}$ & $\begin{array}{l}\text { Maintenance cost for period } t \text {, corresponding to storage capacity } W_{i} \text {, } \\
\text { acquired in period } \tau\left(i=1, \ldots, v_{W} ; t=1, \ldots, T, \tau=1, \ldots, t\right)\end{array}$ \\
\hline$I M_{i t}$ & $\begin{array}{l}\text { Investment required to acquire one unit of production equipment of type } i \text { in } \\
\text { period } t\left(i=1, \ldots, v_{M} ; t=B, \ldots, T\right) \text {. }\end{array}$ \\
\hline$I W_{j i t}$ & $\begin{array}{l}\text { Investment required to increase storage capacity from } W_{j} \text { to } W_{i} \text { in period } t \text { ( } i \\
\left.=1, \ldots, v_{W} ; j=0, \ldots, i-1 ; t=1, \ldots, T\right)\end{array}$ \\
\hline$v_{n i t}^{M}$ & $\begin{array}{l}\text { Variable cost of one unit of product } n \text { produced by production equipment of } \\
\text { type } i \text { in period } t\left(n=1, \ldots, N ; i=1, \ldots, v_{M} ; t=1, \ldots, T\right) \text {. }\end{array}$ \\
\hline$v_{n t}^{W}$ & $\begin{array}{l}\text { Variable storage costs of one unit of product } n \text { in period } t(n=1, \ldots, N ; t= \\
1, \ldots, T) \text {. }\end{array}$ \\
\hline$\gamma_{n k}$ & $\begin{array}{l}\text { Inventory value of one unit of product } n \text { at the end of year } k \text {. It also includes } \\
\gamma_{n 0} \text { defined as the inventory value at the beginning of year } 1(n=1, \ldots, N ; k= \\
0, \ldots, Y) \text {. }\end{array}$ \\
\hline$F C_{t}$ & $\begin{array}{l}\text { Fixed costs (costs that are independent of capacity and level of activity) for } \\
\text { period } t(t=1, \ldots, T) \text {. }\end{array}$ \\
\hline$F P_{t}$ & $\begin{array}{l}\text { Difference between fixed payments (payments that are independent of } \\
\text { capacity and level of activity) and fixed income for period } t(t=1, \ldots, T) \text {. }\end{array}$ \\
\hline
\end{tabular}

Table 3 Financial and tax data

\begin{tabular}{l|l}
\hline \multicolumn{1}{c}{ Symbol } & \multicolumn{1}{c}{ Definition } \\
\hline$\tau^{s}$ & $\begin{array}{l}\text { Number of periods between a sale and reception of collection. } \\
\tau^{p}\end{array}$ \\
$\tau^{b}$ & $\begin{array}{l}\text { Number of periods between the acquisition of variable-cost resources and } \\
\text { the corresponding payment. } \\
\text { Period in the year in which corporate tax is paid (payments would be } \\
\left.\text { made in periods } \Gamma_{1}+\tau^{b}-1, \Gamma_{2}+\tau^{b}-1, \ldots\right) . \\
i_{t}^{b}, i_{t}^{d}\end{array}$ \\
& $\begin{array}{l}\text { Respectively, interest rates applicable to negative and positive balances in } \\
\text { the debit/credit bank account in period } t(t=1, \ldots, T) .\end{array}$
\end{tabular}




\begin{tabular}{l|l}
$r$ & Corporate tax rate. \\
$h_{0}$ & Initial cash balance. \\
$h_{\max }^{-}$ & Maximum negative cash balance (expressed as an absolute value). \\
$\tau^{d M}$ & Integer number of periods to amortise production equipment. \\
$\tau^{d W}$ & Integer number of periods to amortise a storage capacity asset. \\
$k_{\max }$ & Compensation period for tax liabilities from previous periods expressed \\
& in years (integer positive value). \\
$P m x_{k}, L m x_{k}$ & Respectively, upper bounds on profit and loss before tax for year $k(k=$ \\
& $1, \ldots, Y)$.
\end{tabular}

Table 4 Miscelaneous data

\begin{tabular}{|c|c|}
\hline Symbol & Definition \\
\hline$d_{n t}$ & Demand for product $n$ in period $t(n=1, \ldots, N ; t=1, \ldots, T)$. \\
\hline$P S_{t}$ & Income from product sales in period $t\left(t=\max \left(B, 1-\tau^{s}\right), \ldots, T\right)$. \\
\hline$P S I_{t}$ & $\begin{array}{l}\text { Collection in period } t \text { of product sold in previous periods, equal to } P S_{t-\tau^{s}} \text { for } \\
t=\max \left(B+\tau^{s}, 1\right), \ldots, T \text {, and } 0 \text { for } \forall t \mid(t \geq 1) \wedge\left(t \leq B+\tau^{s}-1\right) \text {. }\end{array}$ \\
\hline$\alpha_{n}$ & $\begin{array}{l}\text { Manufacturing capacity required to manufacture one unit of product } n(n= \\
1, \ldots, N) \text {. }\end{array}$ \\
\hline$\beta_{n}$ & Storage capacity required to store one unit of product $n(n=1, \ldots, N)$. \\
\hline $\mathrm{sO}_{n}$ & Initial inventory level of product $n(n=1, \ldots, N)$ \\
\hline$z 0_{i \tau}$ & $\begin{array}{l}\text { Number of units of production equipment of type } i \text { acquired in period } \tau \\
\text { which are available in period } 1\left(i=1, \ldots, v_{M} ; \tau=B, \ldots, 0\right) \text {. }\end{array}$ \\
\hline$M_{i}$ & Manufacturing capacity of one unit of equipment of type $i\left(i=1, \ldots, v_{M}\right)$ \\
\hline$W_{i}$ & $\begin{array}{l}\text { Storage capacity of capacity level } i\left(i=0, \ldots, v_{W}\right) \text { where } W_{0} \text { is the initial } \\
\text { storage capacity (at the beginning of period } 1) \text {. }\end{array}$ \\
\hline$\tau_{i}^{M}$ & $\begin{array}{l}\text { Period in which equipment of type } i \text { is available to be purchased }(i=1, \ldots \text {, } \\
\left.v_{M}\right) \text {. }\end{array}$ \\
\hline$S M_{i t \tau}$ & $\begin{array}{l}\text { Sale price of a unit of production equipment of capacity } M_{i} \text { acquired in } \\
\text { period } \tau \text { and sold at the beginning of period } t\left(i=1, \ldots, v_{M} ; \tau=B, \ldots, T ; t=\right. \\
\max (1, \tau+1), \ldots, T+1) \text {. Period } T+1 \text { is the end of the plannig horizon. }\end{array}$ \\
\hline$S D 0_{t}$ & $\begin{array}{l}\text { Amount of amortisation corresponding to investment in the initial storage } \\
\text { capacity attributable to period } t(t=1, \ldots, T) . S D 0_{t}=0 \text { for } \mathrm{t}>\tau 0^{d W} \text {. }\end{array}$ \\
\hline SWO & Sale price of the initial storage capacity $W_{0}$ sold at the end of time horizon. \\
\hline$S W_{j i t}$ & $\begin{array}{l}\text { Sale price of the increase of storage capacity from } W_{i} \text { to } W_{j} \text { put into service } \\
\text { in period } t \text { and sold at the end of time horizon }\left(i=0, \ldots, v_{W} ; j=1, \ldots, i-1 ; t=\right. \\
1, \ldots, T) \text {. }\end{array}$ \\
\hline
\end{tabular}

Variables: 
The variables are grouped in Tables 5, 6 and 7 according to their relationship to strategic or tactical decisions, or to whether they are auxiliary variables.

Table 5 Strategic decision variables

\begin{tabular}{l|l}
\hline \multicolumn{1}{c}{ Symbol } & \multicolumn{1}{c}{ Definition } \\
\hline$z_{i t \tau}^{M} \in \mathbb{Z}^{+}$ & $\begin{array}{l}\text { Number of units of production equipment of type } i \text { acquired in period } \\
\tau \text { which are available in period } t\left(i=1, \ldots, v_{M} ; t=1, \ldots, T, \tau=B, \ldots, t\right) .\end{array}$ \\
$y_{0 i 1}^{W}, y_{j i t}^{W}$ & $\left.\begin{array}{l}1 \text { if storage capacities in periods } t-1 \text { and } t \text { are, respectively, } W_{j} \text { and } W_{i}(i= \\
\in\{0,1\}\end{array} \quad 0, \ldots, v_{W} ; j=0, \ldots, i ; t=2, \ldots, T\right) ; 0$ otherwise. \\
\hline
\end{tabular}

These variables do not express directly the acquisition and sale of production equipment or expansion of storage capacity. However, there are simple relations between these decisions and the variables of Table 5, as follows:

- Acquiring production equipment of type $i$ in period $t: z_{i t t}^{M}$. The value of the variable is the number of units of production equipment acquired.

- Selling production equipment of type $i$ acquired in period $\tau$ in period $t,: z_{i, t-1, \tau}^{M}$ $z_{i t \tau}^{M}$. The value of the expression is the number of units of production equipment sold.

- Expanding storage capacity up to $W_{j}$ in period $t: \sum_{i=0}^{j-1} y_{i j t}^{W}$. The value of the expression is 1 if the decision is taken.

The variables $z_{i t \tau}^{M}$ and $y_{j i t}^{W}$ facilitate the modelling of several constraints that depend on strategic decisions such as capacity constraints (constraints 2), calculation of capacity maintenance costs $C M P_{t}$ and $V C P_{t}$, and calculation of the amortisation of production equipment and storage capacities $E D_{i t \tau}$ and $S D_{t}$. It would have been more complicated to model these constraints using other variables.

Table 6 Tactical decision variables

\begin{tabular}{l|l}
\hline \multicolumn{1}{l|}{ Symbol } & \multicolumn{1}{c}{ Definition } \\
\hline$q_{\text {nit }} \in \mathbb{R}^{+}$ & $\begin{array}{l}\text { Amount of product } n \text { manufactured by production equipment } i \text { in period } t \\
\left(n=1, \ldots, N ; i=1, \ldots, v_{M} ; t=1, \ldots, T\right) .\end{array}$ \\
$s_{n t} \in \mathbb{R}^{+}$ & \begin{tabular}{l} 
Inventory level of product $n$ in period $t(n=1, \ldots, N ; t=1, \ldots, T)$. \\
\hline
\end{tabular}
\end{tabular}


Table 7 Auxiliary variables

\begin{tabular}{|c|c|}
\hline Symbol & Definition \\
\hline$h_{t}^{+}, h_{t}^{-} \in \mathbb{R}^{+}$ & $\begin{array}{l}\text { Absolute values of positive and negative bank balance, respectively, at } \\
\text { the end of period } t(t=1, \ldots, T) \text {. }\end{array}$ \\
\hline$\theta_{k l} \in \mathbb{R}^{+}$ & $\begin{array}{l}\text { Income tax liability for year } k \text { offset in year } k+l(k=1, \ldots, Y ; l=1, \ldots \text {, } \\
\left.k_{\max }\right) \text {. }\end{array}$ \\
\hline$I T B_{k} \in \mathbb{R}^{+}$ & Income tax base for year $k(k=1, \ldots, Y)$. \\
\hline $\begin{array}{l}P B T_{k}, L B T_{k} \\
\in \mathbb{R}^{+}\end{array}$ & $\begin{array}{l}\text { Absolute values of profit and loss before tax for year } k(k=1, \ldots, Y) \text {, } \\
\text { respectively. }\end{array}$ \\
\hline$y_{k}^{R} \in\{0,1\}$ & $\begin{array}{l}1 \text { if profit before tax for year } k \text { is positive; } 0 \text { if loss before tax for year } k \\
\text { is positive }(k=1, \ldots, Y) \text {. }\end{array}$ \\
\hline$P B_{t} \in \mathbb{R}^{+}$ & Cash balance at the beginnig of period $t(t=1, \ldots, T)$ \\
\hline$E S I_{t} \in \mathbb{R}^{+}$ & Income from production equipment sales in period $t(t=1, \ldots, T)$ \\
\hline$E A P_{t} \in \mathbb{R}^{+}$ & Payments for acquiring production equipment in period $t(t=1, \ldots, T)$. \\
\hline$S A P_{t} \in \mathbb{R}^{+}$ & Payments for changing storage capacity in period $t(t=1, \ldots, T)$ \\
\hline$C M P_{t} \in \mathbb{R}^{+}$ & Payments for capacity maintenance in period $t(t=1, \ldots, T)$. \\
\hline$V C P_{t} \in \mathbb{R}^{+}$ & $\begin{array}{l}\text { Payments of manufacturing and storage variable costs in period } t(t= \\
1, \ldots, T) \text {. }\end{array}$ \\
\hline$T P_{t} \in \mathbb{R}^{+}$ & Corporate tax payments in period $t(t=1, \ldots, T)$ \\
\hline$N A C_{t} \in \mathbb{R}^{+}$ & $\begin{array}{l}\text { Non-amortisable cost of production equipment and storage capacities } \\
\text { acquired in period } t(t=1, \ldots, T) \text {. }\end{array}$ \\
\hline$V C_{t} \in \mathbb{R}^{+}$ & $\begin{array}{l}\text { Variable costs of product manufacture and storage in period } t(t= \\
1, \ldots, T) .\end{array}$ \\
\hline$E D_{i t \tau} \in \mathbb{R}^{+}$ & $\begin{array}{l}\text { Amount of amortisation attributable to period } t \text { of production } \\
\text { equipment } i \text { acquired in period } \tau\left(i=1, \ldots, v_{M} ; t=1, \ldots, T, \tau=B, \ldots, t\right) \text {. }\end{array}$ \\
\hline$S D_{t} \in \mathbb{R}^{+}$ & $\begin{array}{l}\text { Amount of amortisation corresponding to investment in storage } \\
\text { capacity attributable to period } t \text { for assets acquired in that period and in } \\
\text { previous } \tau^{d} \text {-1periods }(t=1, \ldots, T) \text {. }\end{array}$ \\
\hline$P L E S_{i t \tau} \in \mathbb{R}^{+}$ & $\begin{array}{l}\text { Profit/loss from production equipment } i \text { acquired in period } \tau \text {, sold in } \\
\text { period } t\left(i=1, \ldots, v_{M} ; t=1, \ldots, T, \tau=B, \ldots, t-1\right)\end{array}$ \\
\hline$V I V \in \mathbb{R}^{+}$ & Variation of inventory level value in period $t(t=1, \ldots, T)$ \\
\hline
\end{tabular}

Objective function:

The objective function is the cash balance at the end of the planning horizon considering final cash balance, sales income in the last $\tau^{s}$ periods (account receivable), payments for variable costs for the last $\tau^{p}$ periods (account payable), corporate tax payment for the last year, and income from production and storage asset sales. 
maximise $Z=h_{T}^{+}-h_{T}^{-}+\sum_{t=T-\tau^{s}+1}^{T} P S_{t}+\sum_{i=1}^{v_{M}} \sum_{\tau=B}^{T} S M_{i, T+1, \tau} \cdot z_{i, T, \tau}^{M}+S W 0+$

$$
\begin{aligned}
& \sum_{i=1}^{v_{W}} \sum_{t=1}^{T} \sum_{j=0}^{i-1} S W_{j i t} \cdot y_{j i t}^{W}-\sum_{t=T-\tau^{p}+1}^{T} \sum_{i=1}^{v_{M}} \sum_{n=1}^{N} v_{n i t}^{M} \cdot q_{n i t}+ \\
& \sum_{t=T-\tau^{p}+1}^{T} \sum_{n=1}^{N} v_{n t}^{W} \cdot s_{n t}-r \cdot I T B_{Y}
\end{aligned}
$$

where

$$
\sum_{t=T-\tau^{s}+1}^{T} P S_{t}
$$

is the sales income for the last $\tau^{s}$ previous periods,

$$
\sum_{i=1}^{v_{M}} \sum_{\tau=B}^{T} S M_{i, T+1, \tau} \cdot z_{i, T, \tau}^{M}
$$

is the income from production equipment sales at the end of time horizon,

$$
\sum_{i=1}^{v_{W}} \sum_{t=1}^{T} \sum_{j=0}^{i-1} S W_{j i t} \cdot y_{j i t}^{W}
$$

is the income from storage capacity sales at the end of time horizon,

$$
\sum_{t=T-\tau^{p}+1}^{T} \sum_{i=1}^{v_{M}} \sum_{n=1}^{N} v_{n i t}^{M} \cdot q_{n i t}+\sum_{t=T-\tau^{p}+1}^{T} \sum_{n=1}^{N} v_{n t}^{W} \cdot s_{n t}
$$

is the payment of variable costs for the last $\tau^{p}$ periods. Finally, $r \cdot I T B_{Y}$ is the corporate tax payment at the end of planning horizon.

\section{Constraints:}

1. Inventory balance constraints :

$$
\begin{aligned}
& s 0_{n}+\sum_{i=1}^{v_{M}} q_{n i 1}=d_{n 1}+s_{n 1} \quad \forall n \\
& \sum_{i=1}^{v_{M}} q_{n i t}+s_{n, t-1}=d_{n t}+s_{n t} \quad \forall n, t=2, \ldots, T
\end{aligned}
$$

2. Manufacturing and storage capacity constraints ensure that production and storage capacities are not exceeded: 


$$
\begin{array}{ll}
\sum_{n=1}^{N} \alpha_{n} \cdot q_{n i t} \leq M_{i} \cdot \sum_{\tau=B}^{t} z_{i t \tau}^{M} & \forall i, t \\
\sum_{n=1}^{N} \beta_{n} \cdot s_{n t} \leq \sum_{i=0}^{\nu_{W}}\left(W_{i} \cdot \sum_{j=0}^{i} y_{j i t}^{W}\right) & \forall t
\end{array}
$$

3. Bank account balance:

$$
\begin{gathered}
h_{t}^{+}-h_{t}^{-}=P B_{t}+i_{t}^{d} \cdot h_{t}^{+}-i_{t}^{b} \cdot h_{t}^{-}+P S I_{t}+E S I_{t}-F P_{t}-E A P_{t}-S A P_{t}-C M P_{t}-V C P_{t} \\
-T P_{t}
\end{gathered}
$$

The expression of the bank account balance varies from one period $t$ to another. Listed below is each of the relevant entries and its expression for each period $t$ :

$$
\begin{aligned}
& P B_{t}= \begin{cases}h_{0} & t=1 \\
h_{t-1}^{+}-h_{t-1}^{-} & t=2, \ldots, T\end{cases} \\
& E S I_{t}=\left\{\begin{array}{l}
\sum_{i=1}^{v_{M}} \sum_{\tau=B}^{0} S M_{i 1 \tau} \cdot\left(z 0_{i \tau}-z_{i 1 \tau}^{M}\right) \\
\sum_{i=1}^{v_{M}} \sum_{\tau=B}^{t-1} S M_{i t \tau} \cdot\left(z_{i, t-1, \tau}^{M}-z_{i t \tau}^{M}\right) \quad t=2, \ldots, T
\end{array}\right. \\
& E A P_{t}=\sum_{i=1}^{v_{M}}\left(I M_{i t}+C M_{i t}\right) \cdot z_{i t t}^{M} \quad t=1, \ldots, T \\
& S A P_{t}=\sum_{i=1}^{v_{W}} \sum_{j=0}^{i-1}\left(I W_{j i t}+C W_{j i t}\right) \cdot y_{j i t}^{W} \quad t=1, \ldots, T \\
& C M P_{t}=\sum_{i=1}^{v_{M}} \sum_{\tau=B}^{t} M M_{i \tau t} \cdot z_{i t \tau}^{M}+M W 0_{t}+\sum_{i=1}^{v_{W}} \sum_{\tau=1}^{t} \sum_{j=0}^{i-1} M W_{i \tau t} \cdot y_{j i \tau}^{W} \quad t=1, \ldots, T \\
& V C P_{t}= \begin{cases}0 & t=1, \ldots, \tau^{p} \\
\sum_{i=1}^{v_{M}} \sum_{n=1}^{N} v_{n i, t-\tau^{p}}^{M} \cdot q_{n i, t-\tau^{p}}+\sum_{n=1}^{N} v_{n, t-\tau^{p}}^{W} \cdot s_{n, t-\tau^{p}} & t=\tau^{p}+1, \ldots, T\end{cases} \\
& T P_{t}=\left\{\begin{array}{lll}
0 & t \neq \Gamma_{k}-1+\tau^{b}, & k=2, \ldots, Y \\
r \cdot I T B_{k-1} & t=\Gamma_{k}-1+\tau^{b}, & k=2, \ldots, Y
\end{array}\right.
\end{aligned}
$$

4. Financial capacity constraints ensure that the negative bank account balance does not exceed the established limit:

$h_{t}^{-} \leq h_{\max }^{-} \quad t=1, \ldots, T$ 
5. Profit/loss before tax calculation

$$
\begin{aligned}
& P B T_{k}-L B T_{k}= \\
& \sum_{t=\Gamma_{k}}^{\Gamma_{k+1}-1}\left(P S_{t}+i_{t}^{d} \cdot h_{t}^{+}-i_{t}^{b} \cdot h_{t}^{-}-F C_{t}-N A C_{t}-C M P_{t}-V C_{t}-\sum_{i=1}^{v_{M}} \sum_{\tau=B}^{t} E D_{i t \tau}\right. \\
& \left.\quad-S D 0_{t}-S D_{t}+\sum_{i=1}^{v_{M}} \sum_{\tau=B}^{t-1} P L E S_{i t \tau}+V I V_{t}\right)
\end{aligned}
$$

$P B T_{k} \leq P m x_{k} \cdot y_{k}^{R}$

$L B T_{k} \leq L m x_{k} \cdot\left(1-y_{k}^{R}\right)$

where $k=1, \ldots, Y$. The last two sets of constraints ensure that either $P B T_{k}$ or $L B T_{k}$ equals zero; without them, this condition cannot be fulfilled, as can be seen in the following case: suppose that in year $k-k_{\max }$ there were losses that can be offset in year $k$, i.e., year $\mathrm{k}$ is the last year to compensate for them, and suppose that the profit of year $k$ is less than the losses to compensate for. In this case, $P B T_{k}$ will be increased to compensate for all the losses and $L B T_{k}$ will be increased by $P B T_{k}-L B T_{k}$ such that it equals the profit of year $k$.

The items in the profit/loss before tax expression are detailed as follows:

$$
\begin{aligned}
& N A C_{t}=\sum_{i=1}^{v_{M}} C M_{i t} \cdot z_{i t t}^{M}+\sum_{i=1}^{\nu_{W}} \sum_{j=0}^{i-1} C W_{j i t} \cdot y_{j i t}^{W} \quad t=1, \ldots, Y \cdot T \\
& V C_{t}=\sum_{i=1}^{v_{M}} \sum_{n=1}^{N} v_{n i t}^{M} \cdot q_{n i t}+\sum_{n=1}^{N} v_{n t}^{W} \cdot s_{n t} \quad t=1, \ldots, Y \cdot T \\
& E D_{i t \tau}= \begin{cases}\frac{1}{\tau^{d M}} \cdot I M_{i \tau} \cdot z_{i t \tau}^{M} & t=\max (1, \tau), \ldots, \min \left(T, \tau^{d M}+\tau-1\right) \\
0 & t=1+\min \left(T, \tau^{d M}+\tau-1\right), \ldots, T\end{cases} \\
& i=1, \ldots, v_{M}, \tau=B, \ldots, T \\
& S D_{t}= \begin{cases}\sum_{i=1}^{v_{W}} \sum_{\tau=1}^{t} \sum_{j=0}^{i-1} \frac{1}{\tau^{d W}} \cdot I W_{j i \tau} \cdot y_{j i \tau}^{W} & t=1, \ldots, \min \left(T, \tau^{d W}\right) \\
\sum_{W} \sum_{i=1}^{t} \sum_{\tau=1+t-\tau^{d W}}^{i-1} \frac{1}{\tau^{d W}} \cdot I W_{j i \tau} \cdot y_{j i \tau}^{W} & t=1+\min \left(T, \tau^{d W}\right), \ldots, T\end{cases}
\end{aligned}
$$

$P L E S_{i t \tau}=$ 


$$
\begin{aligned}
\bullet & S M_{i 1 \tau} \cdot\left(z 0_{i \tau}-z_{i 1 \tau}^{M}\right)-\left(1-\frac{1-\tau}{\tau^{d M}}\right) \cdot I M_{i \tau} \cdot\left(z 0_{i \tau}-z_{i 1 \tau}^{M}\right) \\
& i=1, \ldots, v_{M}, \tau=B, \ldots, 0 \\
\bullet & S M_{i t \tau} \cdot\left(z_{i, t-1, \tau}^{M}-z_{i t \tau}^{M}\right)-\left(1-\frac{t-\tau}{\tau^{d M}}\right) \cdot I M_{i \tau} \cdot\left(z_{i, t-1, \tau}^{M}-z_{i t \tau}^{M}\right) \\
& i=1, \ldots, v_{M}, \tau=B, \ldots, T, t=2, \ldots, \min \left(T, \tau^{d M}+\tau-1\right) \\
\bullet & S M_{i t \tau} \cdot\left(z_{i, t-1, \tau}^{M}-z_{i t \tau}^{M}\right) \\
& i=1, \ldots, v_{M}, \tau=B, \ldots, T, t=1+\min \left(T, \tau^{d M}+\tau-1\right), \ldots, T \\
V I V_{t}= & \begin{cases}\sum_{n=1}^{N} \gamma_{n 1} \cdot s_{n, 1}-\sum_{n=1}^{N} \gamma_{n 0} \cdot s 0_{n} & t=1 \\
\sum_{n=1}^{N} \gamma_{n t} \cdot s_{n t}-\sum_{n=1}^{N} \gamma_{n, t-1} \cdot s_{n, t-1} & t=2, \ldots, T\end{cases}
\end{aligned}
$$

6. Income tax base calculation:

Determine the corporate tax base in year $k$ taking into account year end results and offsetting of tax liabilities from previous years.

$$
\begin{array}{ll}
L B T_{k} \geq \sum_{l=1}^{k_{\max }} \theta_{k l} & k=1, \ldots, Y \\
I T B_{k}=P B T_{k}-\sum_{l=1}^{k-1} \theta_{k-l, l} & k=1, \ldots, k_{\max } \\
I T B_{k}=P B T_{k}-\sum_{l=1}^{k_{\max }} \theta_{k-l, l} & k=k_{\max }+1, \ldots, Y
\end{array}
$$

7. Production equipment acquisition constraints ensure that the number of units of production equipment acquired in period $\tau$ and available in period $t$ is not greater than that available in the previous period $t-1 \geq \max (1, \tau)$ :

$$
\begin{aligned}
& z_{i 1 \tau}^{M} \leq z 0_{i \tau} \quad i=1, \ldots, v_{M} \quad \tau=B, \ldots, 0 \\
& z_{i t \tau}^{M} \leq z_{i, t-1, \tau}^{M} \quad i=1, \ldots, v_{M} \quad t=2, \ldots, T \quad \tau=B, \ldots, 0 \\
& z_{i t t}^{M}=0 \quad i=1, \ldots, v_{M} \quad t=1, \ldots, \tau_{i}^{M}-1 \\
& z_{i t \tau}^{M} \leq z_{i, t-1, \tau}^{M} \quad i=1, \ldots, v_{M} \quad t=\min \left(2, \tau_{i}^{M}\right), \ldots, T \quad \tau=\tau_{i}^{M}, \ldots, t-1
\end{aligned}
$$

8. Storage capacity acquisition constraints ensure that changes in storage capacity are for expansion purposes: 


$$
\begin{aligned}
& \sum_{k=0}^{v_{W}} y_{0 k 1}^{W}=1 \\
& \sum_{k=j}^{v_{W}} y_{j k 2}^{W}=y_{0 j 1}^{W} \quad j=1, \ldots, v_{W} \\
& \sum_{k=j}^{v_{W}} y_{j k t}^{W}=\sum_{i=0}^{j} y_{i j, t-1}^{W} \quad j=0, \ldots, v_{W} \quad t=3, \ldots, T
\end{aligned}
$$

\section{Computational experiment}

In this section, our model is evaluated for computational efficiency of solving the problem. A computational experiment was conducted where the model was implemented in OPL and solved with ILOG CPLEX 12.6 in Intel Core $3.33 \mathrm{GHz}$ workstations with 4 Gigabytes of RAM operating under Windows-7 (64 bits). We solved 54 instances with the following values: $Y=5,10,20$ with 4, 6, 12 periods per year; $N=1,10,30 ; v_{M}=4 ; v_{W}=3,5$. The files with the input data of each instance can be found at http://www.ioc.upc.edu/EOLI/research/S-SSCPlanning/instances/

Each instance was defined by a great amount of data generated from a few parameters. The expressions and parameters used to generate the instances can be seen in the Appendix.

Undoubtedly, the scale of real world problems shows a great variety concerning the number of periods of the planning horizon, the number of products and the number of types of resources. However, few papers specify the values of these parameters in real applications. In Bermon and Hood (1999) they are equal, respectively, to 20 (however, as the model is solved independently for each period, in fact it is equivalent to 20 models of 1 period), 50 and 3; in Rajagopalan \& Swaminathan (2001), to 16, 10 and 3; in Wang and Lin (2002) the number of periods is 4 and the number of types of resources is 8 (the role of products is played by 20 testing orders, each one of them assigned previously to a type of resource). Therefore, our instances, compared to this three real cases, include very high values of the number of periods (up to 240), and numbers of products (up to 30) and of types of resources (5 plus the storage capacity) of the same order that those reported in the mentioned papers. Note, moreover, that the number of products does not have a great influence on the computational behaviour of the model 
and that reducing the number of periods allows dealing with a greater number of products.

The number of model variables were 3511 (630 integer, 204 binary and 2677 real variables) for the smaller instances and 468281 (86760 integer, 5059 binary and 376462 real variables) for the larger instances. The number of constraints was 3379 and 445635 for the smaller and larger instances, respectively.

The computing time was limited to 3600 s per instance. Although a longer resolution time could also be reasonable (as in this type of problem resolution time is not critical), the time limit was set to $3600 \mathrm{~s}$ in order not to unnecessarily extend the length of the experiment. Table 8 shows the computing time (column $t$ ) and relative gap corresponding to the best feasible solution obtained for all instances. Note that, although some instances are not solved within the specified time, the relative gap is small.

Table 8. Resolution times for instances solved within $3600 \mathrm{~s}$ and relative gaps for instances not solved within $3600 \mathrm{~s}$.

\begin{tabular}{|c|c|c|c|c|c|c|c|c|c|c|}
\hline$Y$ & $T$ & $N$ & $v_{W}$ & $t$ & $Y$ & $T$ & $N$ & $v_{W}$ & $t$ & $\begin{array}{l}\text { Relative } \\
\text { gap (\%) }\end{array}$ \\
\hline 5 & 20 & 1 & 3 & 0,6 & 5 & 60 & 30 & 3 & 3600,3 & 0,79 \\
\hline 5 & 20 & 1 & 5 & 0,7 & 5 & 60 & 30 & 5 & 3600,3 & 2,33 \\
\hline 5 & 20 & 10 & 3 & 1,9 & 10 & 120 & 1 & 3 & 3600,4 & 4,79 \\
\hline 5 & 20 & 10 & 5 & 1,9 & 10 & 120 & 1 & 5 & 3601,2 & 3,97 \\
\hline 5 & 20 & 30 & 3 & 7,1 & 10 & 120 & 10 & 3 & 3600,9 & 1,93 \\
\hline 5 & 20 & 30 & 5 & 7,4 & 10 & 120 & 10 & 5 & 3601,7 & 1,83 \\
\hline 5 & 30 & 1 & 3 & 1,9 & 10 & 120 & 30 & 3 & 3600,4 & 2,13 \\
\hline 5 & 30 & 1 & 5 & 2,9 & 10 & 120 & 30 & 5 & 3600,4 & 1,66 \\
\hline 5 & 30 & 10 & 3 & 5,5 & 20 & 80 & 1 & 3 & 3600,5 & 1,75 \\
\hline 5 & 30 & 10 & 5 & 6,1 & 20 & 80 & 1 & 5 & 3600,6 & 1,94 \\
\hline 5 & 30 & 30 & 3 & 19,4 & 20 & 80 & 10 & 3 & 3600,6 & 1,52 \\
\hline 5 & 30 & 30 & 5 & 24,5 & 20 & 80 & 10 & 5 & 3600,7 & 1,40 \\
\hline 5 & 60 & 1 & 3 & 35,6 & 20 & 80 & 30 & 3 & 3600,8 & 1,85 \\
\hline 5 & 60 & 1 & 5 & 36,7 & 20 & 80 & 30 & 5 & 3600,4 & 2,29 \\
\hline 5 & 60 & 10 & 3 & 461,7 & 20 & 120 & 1 & 3 & 3601,0 & 2,29 \\
\hline 5 & 60 & 10 & 5 & 338,9 & 20 & 120 & 1 & 5 & 3601,2 & 2,57 \\
\hline 10 & 40 & 1 & 3 & 38,8 & 20 & 120 & 10 & 3 & 3600,9 & 2,04 \\
\hline 10 & 40 & 1 & 5 & 31,8 & 20 & 120 & 10 & 5 & 3601,0 & 2,07 \\
\hline 10 & 40 & 10 & 3 & 12,9 & 20 & 120 & 30 & 3 & 3600,5 & 2,85 \\
\hline 10 & 40 & 10 & 5 & 12,5 & 20 & 120 & 30 & 5 & 3600,7 & 3,05 \\
\hline 10 & 40 & 30 & 3 & 15,7 & 20 & 240 & 1 & 3 & 3601,3 & 3,80 \\
\hline 10 & 40 & 30 & 5 & 15,8 & 20 & 240 & 1 & 5 & 3600,7 & 3,71 \\
\hline 10 & 60 & 1 & 3 & 345,8 & 20 & 240 & 10 & 3 & 3600,4 & 3,21 \\
\hline
\end{tabular}




\begin{tabular}{l|l|l|l|rl|l|l|l|l|l}
10 & 60 & 1 & 5 & 368,6 & 20 & 240 & 10 & 5 & 3600,5 & 3,36 \\
10 & 60 & 10 & 3 & 188,1 & 20 & 240 & 30 & 3 & 3600,6 & 4,10 \\
10 & 60 & 10 & 5 & 249,1 & 20 & 240 & 30 & 5 & 3600,7 & 4,11 \\
10 & 60 & 30 & 3 & 109,3 & & & & & & \\
10 & 60 & 30 & 5 & 87,9 & & & & &
\end{tabular}

Instances not solved within $3600 \mathrm{~s}$ were executed again but now the computing time was limited to $43200 \mathrm{~s}$ (12 hours). Table 9 summarises the results. Note that, although the computing time was increased from 1 hour to 12 hours, the new relative gaps were very similar to those obtained within $3600 \mathrm{~s}$.

Table 9. Resolution times for instances solved within $43200 \mathrm{~s}$ and relative gaps for instances not solved within $3600 \mathrm{~s}$.

\begin{tabular}{r|r|r|r|r|r}
\hline \multicolumn{1}{r}{$T$} & \multicolumn{1}{c}{$N$} & \multicolumn{1}{c}{$v_{W}$} & \multicolumn{1}{c}{$\begin{array}{r}\text { Realitive } \\
\text { gap (\%) }\end{array}$} \\
\hline 5 & 60 & 30 & 3 & 3728,7 & \\
5 & 60 & 30 & 5 & 7579,6 & \\
10 & 120 & 1 & 3 & 43203,9 & 2,93 \\
10 & 120 & 1 & 5 & 26165,9 & \\
10 & 120 & 10 & 3 & 13749,2 & \\
10 & 120 & 10 & 5 & 13796,3 & \\
10 & 120 & 30 & 3 & 11908,2 & \\
10 & 120 & 30 & 5 & 10047,3 & \\
20 & 80 & 1 & 3 & 43203,9 & 1,21 \\
20 & 80 & 1 & 5 & 43203,3 & 1,28 \\
20 & 80 & 10 & 3 & 43203,5 & 1,14 \\
20 & 80 & 10 & 5 & 43203,4 & 1,01 \\
20 & 80 & 30 & 3 & 43203,6 & 1,31 \\
20 & 80 & 30 & 5 & 43203,6 & 1,56 \\
20 & 120 & 1 & 3 & 43201,9 & 1,81 \\
20 & 120 & 1 & 5 & 43202,0 & 2,20 \\
20 & 120 & 10 & 3 & 43202,3 & 1,68 \\
20 & 120 & 10 & 5 & 43202,1 & 1,54 \\
20 & 120 & 30 & 3 & 43202,3 & 2,05 \\
20 & 120 & 30 & 5 & 43202,6 & 2,02 \\
20 & 240 & 1 & 3 & 43206,7 & 3,17 \\
20 & 240 & 1 & 5 & 43210,9 & 3,46 \\
20 & 240 & 10 & 3 & 43206,8 & 2,50 \\
20 & 240 & 10 & 5 & 43216,9 & 2,46 \\
20 & 240 & 30 & 3 & 43209,9 & 3,27 \\
20 & 240 & 30 & 5 & 43227,6 & 3,20
\end{tabular}


Linear relaxation of each instance was also solved to check its resolution time and integrality gap. Computing times were less than $49 \mathrm{~s}$ and the values of the corresponding objective function were $2.4 \%$ to $7.7 \%$ higher than the best integer solution found.

Because of the financial capacity constraints (constraints 4), the solutions of the problem are always bounded. Given that the demand in each period must be fully satisfied (constraints 1), the problem might not be feasible, for example, when the maximum negative cash balance is not sufficient for the acquisition of necessary production equipment to supply the demand. In our experiment, all instances have feasible solutions.

Our model can be used to study the influence of some factors on results. For example, many models in the literature consider a small number of periods per year in order to reduce model size. The instances in our computational experiment may be used to determine the impact of the number of periods per year on the solution. Figure 1 summarises the results for instances with $Y=10, N=1$ and $v_{W}=5$. In the solution of the instance with $T=40$, the investment in storage capacity is in period 3 ( 0.75 years) while in the instances with $T=60$ and $T=120$, the same decision is taken, respectively, in periods 6 (0.83 years) and 8 (0.66 years).
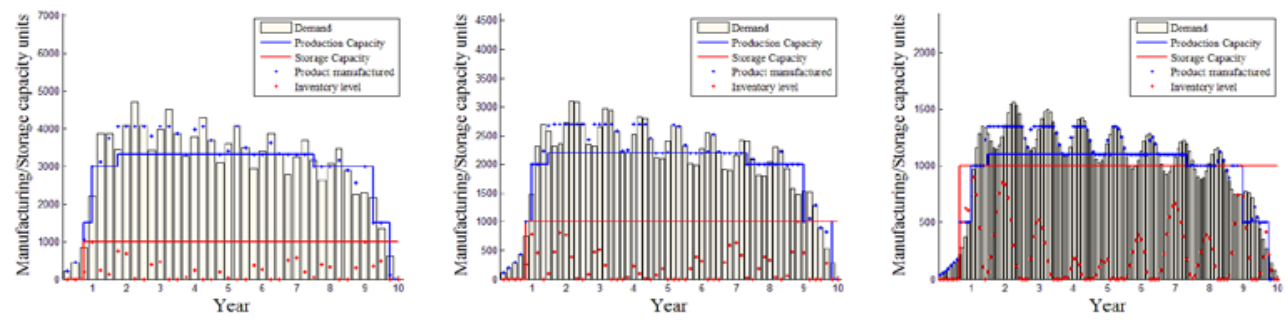

Figure 1: Demand, production and storage capacities, products manufactured and inventory levels for the results of instances with $Y=10, N=1$ and $v_{W}=5$.

The results obtained with our model can be used to analyse some characteristics of the solution. For example, we can answer some managerial questions such as: What are the dominant costs? Or, is it optimal to use a single type of equipment? The answer to this type of questions obviously depends on the data sets used and cannot be extrapolated when other data sets are used. Regarding the first question, the results of our computational experiment show that the dominant costs correspond to the variable cost of manufacturing and storage products. However, in other settings the dominant role 
may be played by financial or variable production costs. Regarding the second question, again, no general behaviour can be expected to this respect. Of course, if more productive technologies are supposed to be available within the planning horizon, the optimal policy will involve more than one type of equipment. Even without technological progress, it may be convenient to use a diversity of equipment because this way production capacity can fit better to the demand. With our data, equipment types 1 and 2 are always used and for some instances type 3 is used too.

\section{Conclusions and further research}

In this article, we proposed a mixed-integer linear programming model for strategic capacity planning of a single-site manufacturing system which includes the major factors in a strategic capacity planning decision process. It is a deterministic model with discrete time and finite horizon. The model takes into account the most important issues in a productive system and integrates the production and cash flows.

In the production flow, acquisition, renewal and sale of production equipment are modelled, and so are acquisition and expansion of storage capacity, as well as the detailed production plan. In the cash flow, the model considers the financial income of deposits and cost of credit accounts, maintenance costs of production equipment and storage capacities, variable cost of manufacturing, accounts payable and receivable, and corporate tax.

We solved the model with CPLEX using instances of several dimensions. Resolution time was less than 1 hour for instances with a time horizon of 60 periods and up to 30 types of products. For larger instances, with a time horizon of 120 and 240 periods, the optimal solution was not achieved within the allowed computing time, but the relative gap was not greater than $4.1 \%$.

Traditional models that deal with strategic capacity decisions in production systems include only some of the relevant issues in our model, and often only partially. For example, many do not to consider storage capacities or borrowing capacity, which limits their use when decisions based on their solutions must be made. Our model, on the other hand, provides more realistic solutions that can be useful from the point of view of strategic management. Since it includes all the above aspects and is solved in a reasonable time, our model may be used as a tool for supporting strategic capacity planning decision making. 
We propose as future work to enhance the model by including more relevant business flows and improving the treatment of already incorporated flows. An example of a new flow is the reverse logistics flow. The treatment of financial flows can be enhanced by incorporating more financial options. Likewise, the treatment of the production flow can be improved by considering working time organisation. Finally, the model can serve as a basis of a scenario-based stochastic model.

\section{References}

Atamtürk, A., \& Hochbaum, D. S. (2001). Capacity acquisition, subcontracting, and lot sizing. Management Science, 47(8): 1081-1100.

Bermon, S. \& Hood, S. J. (1999). Capacity Optimization Planning System (CAPS). Interfaces, 29 (5): 31-50.

Bradley, J. R., \& Glynn, P. W. (2002). Managing capacity and inventory jointly in manufacturing systems. Management Science, 48(2), 273-288.

Çatay, B., Erengüç, S. S., \& Vakharia, A. J. (2003). Tool capacity planning in semiconductor manufacturing. Computers \& Operations Research, 30(9), 13491366.

Chand, S., McClurg, T., \& Ward, J. (2000). A model for parallel machine replacement with capacity expansion. European Journal of Operational Research, 121 (3), 519-531.

Chen, Y.Y., Chen, T.L., \& Liou, C.D. (2013). Medium-term multi-plant capacity planning problems considering auxiliary tools for the semiconductor foundry. International Journal of Advanced Manufacturing Technology, 64 (9-12), 12131230.

Geng, N. \& Jiang, Z. (2009). A review on strategic capacity planning for the semiconductor manufacturing sector. International Journal of Production Research, 47(13), 3639-3655.

Geng, N., Jiang, Z., \& Chen, F. (2009). Stochastic programming based capacity planning for semiconductor wafer fab with uncertain demand and capacity. European Journal of Operation Research 198(3), 899-908.

Julka, N., Baines, T., Tjahjono, B., Lendermann, P, \& Vitanov, V. (2007). A review of multifactor capacity expansion models for manufacturing plants: Searching for a 
holistic decision aid. International Journal of Production Economics, 106 (2), 607-621.

Lim, J. S., Manan, Z. A., Alwi, S. R. W., \& Hashim, H. (2013). A multi-period model for optimal planning of an integrated, resource-efficient rice mill. Computers and Chemical Engineering, 52 (10), 77-89.

Luss, H. (1982). Operations research and capacity expansion problems: A survey. Operations Research, 30(5), 907-947.

Martínez-Costa, C., Mas-Machuca, M., Benedito, E. \& Corominas, A. (2014). A review of mathematical programming models for strategic capacity planning in manufacturing. International Journal of Production Economics, 153, 66-85.

Mitra, S., Pinto, J.M., \& Grossmann, I.E. (2014). Optimal multi-scale capacity planning for power-intensive continuous processes under time-sensitive electricity prices and demand uncertainty, Part I: modeling. Computers \& Chemical Engineering 65, 89-101

Olhager, J., Rudberg, M., \& Wikner, J. (2001). Long-term capacity management: Linking the perspective from manufacturing strategy and sales and operations planning. International Journal of Production Economics, 69(2), 215-225.

Rajagolapan, S. (1992). Deterministic capacity expansion under deterioration. Management Science, 38(4), 525-539.

Rajagopalan, S., \& Soteriou, A.C. (1994), Capacity Acquisition and Disposal with Discrete Facility Sizes. Management Science, 40 (7), 903-917.

Rajagolapan, S. (1998). Capacity expansion and equipment replacement: a unified approach. Operations Research, 46(6), 846-857.

Rajagopalan, S. \& Swaminathan, J. M. (2001). A coordinated production planning model with capacity expansion and inventory management. Management Science, 47(11), 1562-1580.

Thomas, B.G., \& Bollapragada, S. (2010). General electric uses an integrated framework for product costing, demand forecasting, and capacity planning of new photovoltaic technology products. Interfaces 40 (5), 353-367. 
Van Mieghem, J. A. (2003). Capacity management, investment and hedging: Review and recent developments. Manufacturing \& Service Operations Management, 5(4), 269-302.

Wang, K.J., \& Lin, S. H. (2002). Capacity expansion and allocation for a semiconductor testing facility under constrained budget. Production Planning \& Control, 13(5), 429-437.

Wang, K.J., \& Hou, T.C. (2003). Modelling and resolving the joint problem of capacity expansion and allocation with multiple resources and a limited budget in the semiconductor testing industry. International Journal of Production Research, 42 (14), 3217-3235.

Wang, S.M., Chen, J.C., \& Wang, K.-J. (2007a). Resource portfolio planning of maketo-stock products using a constraint programming-based genetic algorithm. Omega, 35 (2), 237-246.

Wang, K.J., Wang, S.M., \& Yang, S.J. (2007b). A resource portfolio model for equipment investment and allocation of semiconductor testing industry. European Journal of Operational Research, 179 (2), 390-403.

Wu, S. D., Erkoc, M., \& Karabuk, S. (2005). Managing capacity in the high-tech industry: A review of literature. The Engineering Economist, 50(2), 125-158.

Yang, S.-J.S., Yang, F.-C.,Wang, K.-J., Chandra, Y., 2009. Optimising resource portfolio planning for capital-intensive industries under process-technology progress. International Journal of Production Research, 47 (10), 2625-2648.

Zhang, R., Zhang, L., Xiao, \& Y., Kaku, I. (2012). The activity-based production planning with capacity expansion, Computers \& Industrial Engineering, 62 (2), 491-503.

\section{Appendix}

In this appendix, we describe how data for the computational experiment instances were obtained by showing the expressions and parameters used to calculate them. Tables A.1, A.2 and A.3 show the expressions whereas Tables A.4, A.5 and A.6 show the parameters.

Table A.1 Expressions used to calculate dimensional data 


\begin{tabular}{l|l}
\hline Symbol & \multicolumn{1}{|c}{ Expression/Value } \\
\hline$P$ & $T / Y$ \\
$\Gamma_{k}$ & $1+k \cdot(P-1)$ \\
$B$ & 1 \\
\hline
\end{tabular}

Table A.2 Expressions used to calculate investment and cost data

\begin{tabular}{|c|c|}
\hline Symbol & Expression/Value \\
\hline$C M_{i, k \cdot P+t}$ & $C M 0_{i} \cdot M_{i} \cdot P \cdot p 0_{1} \cdot(1+\Delta c)^{k}$ \\
\hline$C W_{i j, k \cdot P+t}$ & $C W 0_{i j} \cdot p 0_{1} \cdot\left(W_{j}-W_{i}\right) \cdot(1+\Delta c)^{k}$ \\
\hline$I M_{i, k \cdot P+t}$ & $I M 0_{i} \cdot M_{i} \cdot P \cdot p 0_{1} \cdot(1+\Delta c)^{k}$ \\
\hline$I W_{i j, k \cdot P+t}$ & $I W 0_{i j} \cdot p 0_{1} \cdot\left(W_{j}-W_{i}\right) \cdot(1+\Delta c)^{k}$ \\
\hline$M M_{i \tau t}$ & $\frac{M M 0}{P} \cdot I M_{i t} \cdot(1+\Delta M)^{\frac{t-\tau}{P}}$ \\
\hline$M W 0_{t}$ & 0 \\
\hline$M W_{i \tau t}$ & $\frac{M W 00}{P} \cdot I W_{1 i t} \cdot(1+\Delta W)^{\frac{t-\tau}{P}}$ \\
\hline$v_{n i, k \cdot P+t}^{M}$ & $v 0_{n i}^{M} \cdot p 0_{n} \cdot(1+\Delta c)^{k}$ \\
\hline$v_{n, k \cdot P+t}^{W}$ & $\frac{v 0_{n}^{W}}{P} \cdot p 0_{n} \cdot(1+\Delta c)^{k}$ \\
\hline$\gamma_{n k}$ & $0.6 \cdot p 0_{n} \cdot\left(1+\Delta p_{n}\right)^{k}$ \\
\hline$F C_{k \cdot P+t}$ & $\frac{F C 0}{P} \cdot(1+\Delta c)^{k}$ \\
\hline$F P_{k \cdot P+t}$ & $\frac{F P 0}{P} \cdot(1+\Delta c)^{k}$ \\
\hline
\end{tabular}

Table A.3 Expressions used to calculate financial, tax and miscellaneous data

\begin{tabular}{l|l|l|l|}
\hline Symbol & Expression/Value & Symbol & Expression/Value \\
\hline
\end{tabular}




\begin{tabular}{|c|c|c|c|}
\hline$\tau^{S}$ & $\operatorname{int}\left(\tau 0^{S} \cdot P+0.5\right)$ & $P S_{k \cdot P+t}$ & $\sum_{n=1}^{N} p 0_{n} \cdot\left(1+\Delta p_{n}\right)^{k} \cdot d_{n t}$ \\
\hline$\tau^{p}$ & $\operatorname{int}\left(\tau 0^{p} \cdot P+0.5\right)$ & $\alpha_{n}$ & 0.7 to 1.5 \\
\hline$\tau^{b}$ & $\operatorname{int}\left(\tau 0^{b} \cdot P+0.5\right)$ & $\beta_{n}$ & 0.7 to 1.5 \\
\hline$i_{t}^{b}$ & $\left(1+i 0^{b}\right)^{\frac{1}{P}}-1$ & $s 0_{n}$ & $(0,0,0)$ \\
\hline$i_{t}^{d}$ & $\left(1+i 0^{d}\right)^{\frac{1}{P}}-1$ & $M_{i}$ & $M 0_{i} \cdot \frac{\sum_{n=1}^{N} \alpha_{n} \cdot d 0_{n}}{P}$ \\
\hline$r$ & 0.25 & $W_{i}$ & $(0 ; 200 ; 500 ; 1000 ; 1500 ; 2000)$ \\
\hline$h_{0}$ & 0 & $\tau_{i}^{M}$ & 1 \\
\hline$h_{\max }^{-}$ & 5000000 & $S M_{i t \tau}$ & $\begin{aligned} S M 0 \cdot e^{-S M 1 \cdot \frac{t-\tau}{P}} \cdot I M_{i t} \\
\cdot(1+\Delta M)^{\frac{t-\tau}{P}}\end{aligned}$ \\
\hline$\tau^{d M}$ & $5 \cdot P$ & $S D 0_{t}$ & 0 \\
\hline$\tau^{d W}$ & $5 \cdot P$ & SW0 & 0 \\
\hline$k_{\max }$ & 4 & $S W_{j i t}$ & $\begin{aligned} S W 0 \cdot e^{-S W 1 \cdot \frac{Y \cdot T+1-t}{P}} \cdot I W_{j i t} \\
\cdot(1+\Delta W)^{\frac{Y \cdot T+1-t}{P}}\end{aligned}$ \\
\hline$d_{n t}$ & $d 0_{n} \cdot f_{Y, P}(t)$ & & \\
\hline
\end{tabular}

Table A.4 Set of parameters used to calculate the data. The parameters depend neither on $N$ nor on $v_{W}$.

\begin{tabular}{l|l|l|l|l}
\hline \multicolumn{1}{|c|}{ Symbol } & \multicolumn{1}{|c|}{ Value } & & \multicolumn{1}{|c}{ Symbol } & \multicolumn{1}{|c}{ Value } \\
\hline$C M 0_{i}$ & 0 & & $i 0^{d}$ & 0.03 \\
$I M 0_{i}$ & $(0,1.00,0.62)$ & $i 0^{b}$ & 0.08 \\
$M M 0$ & 0.15 & $M 0_{i}$ & $(0.25,0.10,0.50)$ \\
$M W 00$ & 0.04 & $S M 0$ & 0.8 \\
$F C 0$ & 100000 & $S M 1$ & 1.0
\end{tabular}




\begin{tabular}{l|l|l|l}
$F P 0$ & 100000 \\
$\tau 0^{S}$ & $2 / 12$ & $\mid \begin{array}{l}S W 0 \\
S W 1\end{array}$ \\
$\tau 0^{p}$ & $2 / 12$ & & 0.8 \\
$\tau 0^{b}$ & $6 / 12$ & $\Delta c$ & 0.02 \\
$\Delta M$ & 0.0824 \\
$\Delta W$ & 0.0406 \\
\hline
\end{tabular}

Table A.5 Set of parameters that depend on $v_{W}$ used to calculate the data

\begin{tabular}{|c|c|c|c|c|c|c|c|c|c|}
\hline \multirow{2}{*}{ Symbol } & \multicolumn{9}{|c|}{ Value } \\
\hline & \multicolumn{3}{|c|}{$v_{w}=3$} & \multicolumn{6}{|c|}{$v_{w}=5$} \\
\hline \multirow[t]{2}{*}{$C W 0_{i}$} & \multicolumn{3}{|l|}{$(0 ; 0 ; 0)$} & \multicolumn{6}{|c|}{$(0 ; 0 ; 0 ; 0 ; 0)$} \\
\hline & & & & - & 1.00 & 0.90 & 0.85 & 0.85 & 0.85 \\
\hline \multirow{4}{*}{$I W 0_{i j}$} & \begin{tabular}{l|l}
- & 1.00
\end{tabular} & 0.90 & 0.85 & - & - & 0.95 & 0.90 & 0.90 & 0.90 \\
\hline & \begin{tabular}{l|l}
- & - \\
\end{tabular} & 0.95 & 0.90 & - & - & - & 0.95 & 0.95 & 0.95 \\
\hline & - & - & 0.95 & - & - & - & - & 0.95 & 0.95 \\
\hline & & & & - & - & - & - & - & 0.95 \\
\hline
\end{tabular}

Table A.6 Set of parameters that depend on $N$ used to calculate the data

\begin{tabular}{l|l|l|l}
\hline \multirow{2}{*}{ Symbol } & \multicolumn{2}{|c|}{ Value } & \\
\cline { 2 - 4 } & $N=1$ & \multicolumn{1}{|c}{$N=10$} & \multicolumn{1}{|c}{$N=30$} \\
\hline$d 0_{n}$ & 12000 & 40 to 1025 & 150 to 2600 \\
$p 0_{n}$ & 100 & 30 to 200 & 80 to 200 \\
$\Delta p_{n}$ & 0.02 & 0.02 & 0.02 \\
$v 0_{n}^{W}$ & 0.10 & 0.09 to 0.15 & 0.09 to 0.15 \\
$v 0_{n 1}^{M}$ & 0.60 & 0.6 & 0.6 \\
$v 0_{n 2}^{M}$ & 0.31 & 0.28 to 0.31 & 0.28 to 0.31 \\
$v 0_{n 3}^{M}$ & 0.27 & 0.24 to 0.27 & 0.24 to 0.27 \\
\hline
\end{tabular}

The demand pattern $f_{Y, P}(t)$ is calculated from

$$
f_{Y, P}(t)=N o r m \cdot g_{Y, P}(t) \cdot\left(1+\Delta S \cdot \sin \left(\frac{2 \pi t}{P}\right)\right)
$$


where $\Delta S=0.15$, and

$g_{Y, P}(t)= \begin{cases}25^{\frac{t-y_{1} \cdot P}{y_{1} \cdot P}} & t \leq y_{1} \cdot P \\ 2 \cdot[1+P \cdot \log (1+\Delta g)]^{t-t_{1}}-25^{-\frac{t-y_{1} \cdot P}{y_{1} \cdot P}} & y_{1} \cdot P<t \leq y_{2} \cdot P \\ g_{Y, T}\left(y_{2} \cdot P\right) \cdot\left[1-\left(\frac{t-y_{2} \cdot P}{Y \cdot T-y_{2} \cdot P}\right)^{2}\right] & y_{2} \cdot P<t \leq Y \cdot P\end{cases}$

$N o r m=\frac{1}{Y} \sum_{t=1}^{Y \cdot P} g_{Y, P}(t) \cdot\left(1+\Delta S \cdot \sin \left(\frac{2 \pi t}{P}\right)\right)$

with $\Delta g=-0.05, y_{1}=1$, and $y_{2}=Y-2$.

$f_{Y, P}(t)$ follows the product life cycle phases with three distinctive stages: introduction ( $t$ $\left.=1, \ldots, y_{1} \cdot P\right)$, maturity $\left(t=y_{1} \cdot P+1, \ldots, y_{2} \cdot P\right)$ and decline $\left(t=y_{2} \cdot P+1, \ldots, Y \cdot P\right)$ of the product in the market. The stage of maturity has a downward trend in the long term given by the term $\Delta g=-0.05$. The demand pattern has a seasonal behaviour with intensity $\Delta S=0.15$ and periodicity of one year.

Figure A.1 is the graph of functions $f_{Y, P}(t)$.
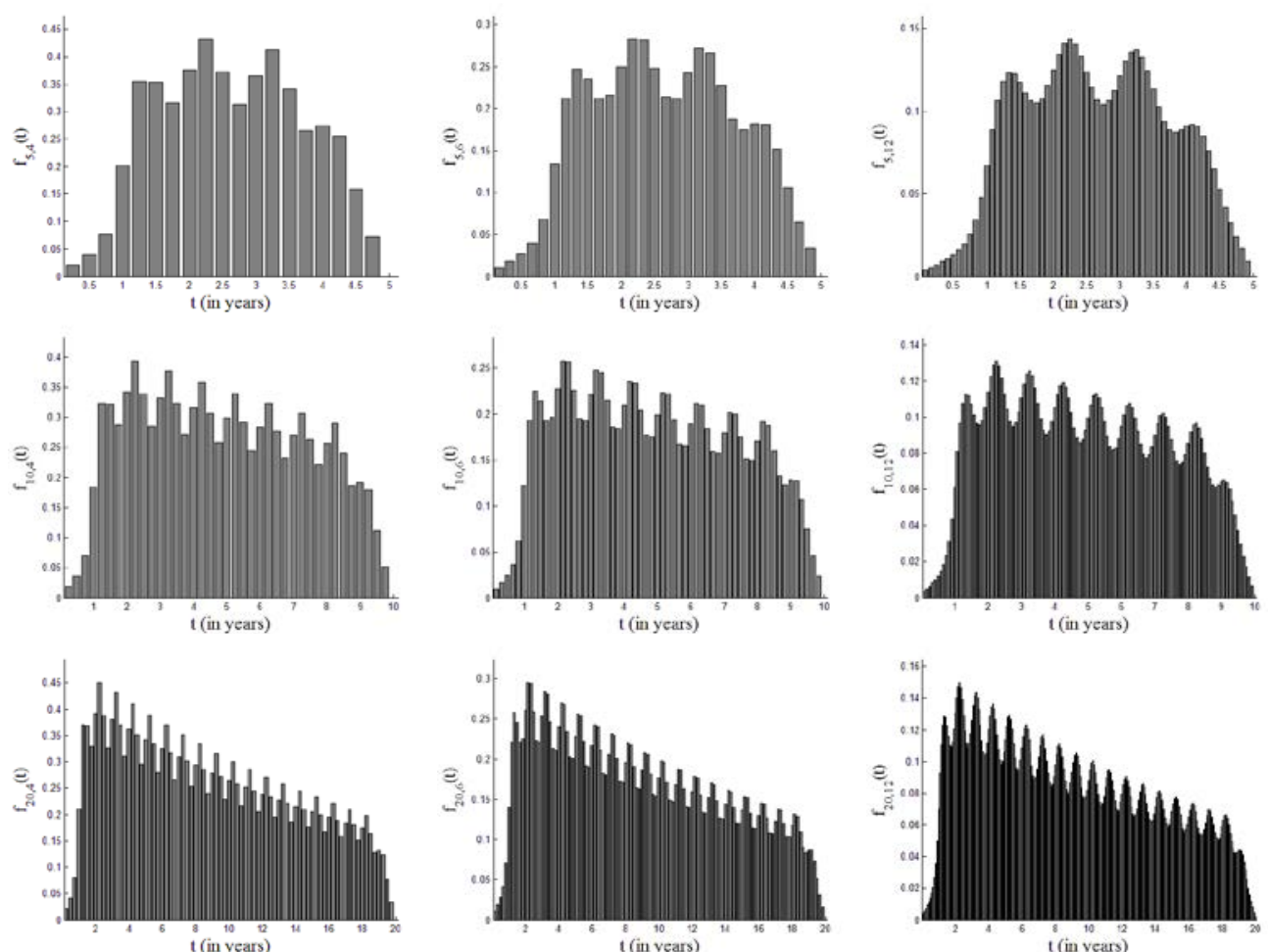

Fig. A.1. Graph of functions $f_{Y, P}(\mathrm{t})$ showing the demand patterns of the instances. 